\title{
Unstructured vs. Structured Use of Laptops in Higher Education
}

\author{
Robin H. Kay and Sharon Lauricella \\ University of Ontario Institute of Technology, \\ Oshawa, Ontario, Canada \\ robin.kay@uoit.ca; sharon.lauricella@uoit.ca
}

\section{Executive Summary}

A majority of today's higher education students have been nurtured on a steady diet of technology and Internet access, leading to the increased presence of laptops in higher education classrooms. However, many instructors are unsure whether or how to assimilate this technology into their lessons. The purpose of the following study was to examine the impact of unstructured (limited use) vs. structured (active use) use of laptops for 177 university students ( 89 males, 88 females). Both on-task (note taking, academic activities) and off-task (email, instant messaging, games, movies) behaviours were examined by surveying students. Paired-t-tests revealed that structured use of laptops resulted in significantly more time spent on note taking and academic activities and significantly less time spent on sending personal emails, instant messages and playing games during class. It is concluded that future research needs to focus on evaluating specific strategies that maximize the benefits and minimize the distractions of using laptops.

Keywords: teaching strategy, evaluation, challenges, distractions, laptop; pedagogy; structured; unstructured; higher education; university; college

\section{Introduction}

The presence of laptops in higher education classrooms has increased markedly in the past five years for at least three reasons. First, today's generation of higher education students has grown up immersed in technology and the Internet. They expect to have constant access to a wide range of technological tools and laptops are an obvious choice in the classroom (Montgomery, 2009; Palfrey \& Gasser, 2008; Tapscott, 2008). Second, the price of mobile devices has dropped enough so that almost any college student can afford a laptop. In fact, in the annual ECAR Study looking at over 100 colleges and universities in North America, almost $90 \%$ of higher education students reported owning a laptop computer in 2009 (Smith, Salaway, \& Caruso, 2009). Third, a number of universities offer wireless access to the Internet inside the classroom. Therefore, stu-

Material published as part of this publication, either on-line or in print, is copyrighted by the Informing Science Institute. Permission to make digital or paper copy of part or all of these works for personal or classroom use is granted without fee provided that the copies are not made or distributed for profit or commercial advantage AND that copies 1) bear this notice in full and 2) give the full citation on the first page. It is permissible to abstract these works so long as credit is given. To copy in all other cases or to republish or to post on a server or to redistribute to lists requires specific permission and payment of a fee. Contact Publisher@InformingScience.org to request redistribution permission. dents can access a wide range of information, both academic and nonacademic, while they are attending class.

Because the increase of laptop use in higher education is driven by external forces, there appears to be no set protocol for using these tools in the classroom. Neither the professors nor the students fully understand what is appropriate laptop behaviour (Lindroth \& 
Bergquist, 2010). This uncertain laptop culture has resulted in at least three pedagogical reactions from instructors: reject, ignore, or accept.

\section{Rejecting Laptops}

The popular media has documented a number of cases where instructors were so frustrated with student off-task behaviour in class that they refused to allow laptops to be used or turned off the wireless connections altogether (Kladko, 2005; McWilliams, 2005; Schwartz, 2003; Szaniszlo, 2006; Young, 2006). This sets up an unfortunate "professor vs. technology" confrontation that will not help higher education in the long run. Outright bans on technology also send a message that students are not to be trusted to take responsibility for their own learning. Furthermore, excessive restraints limit professors who may want to use technology in their lessons (Fang, 2009). Ultimately, it is unlikely that a restrictive approach will gain considerable momentum given that one of the principles of higher education is academic freedom (Furedy, 2000).

\section{Ignoring Laptops (Unstructured Use)}

The second option for a professor is to simply ignore the presence of student laptops and continue using the stalwart of higher education pedagogy - the traditional lecture. This option permits students to choose what they do with their laptops and is sometimes referred to as an "unstructured" approach (Fried, 2008). However, maintaining the status quo and ignoring the presence of laptops can be a risky business and lead to extensive off-task behaviour (Fried, 2008; Grace-Martin \& Gay, 2001; Hembrooke \& Gay, 2003; Medina, 2008; Wurst, Smarkola \& Gaffney, 2008).

Medina (2008) claims that human attention span is limited to about 10 minutes, after which people begin to get restless. Given that most lectures are one to three hours in duration, it is inevitable students will get bored. With a whole host of distractions at their fingertips, some level of educational material being presented is bound to be lost to students. Years ago, Goffman (1963) described this situation as one where subordinate activity competes with dominant activity. In the case where laptops are used within a lecture-based forum, student attention can easily shift from the dominant activity (the lecture) to the subordinate activity (personally engaging web-based pursuits) within ten minutes. Studies where instructors use an unstructured approach to using laptops report that that students are less satisfied (Wurst, Smarkola, \& Gaffney, 2008), engaged in more non-academic activities (Fried, 2008; Grace-Martin \& Gay, 2001), and learn less (Fried, 2008; Grace-Martin \& Gay, 2001; Hembrooke \& Gay, 2003). A number of researchers have concluded that if faculty do not make an active attempt to meaningfully integrate technology into the classroom, distractions and decreased performance are inevitable (Baron et al., 2008; Hall \& Elliot, 2003; Kolar, Sabatini,\& Fink, 2002; McVay, Snyder, \& Graetz, 2005; Weaver \& Nilson, 2005).

\section{Accepting Laptops (Structured Use)}

A third reaction to the increased presence of laptops in higher education classrooms is to use this technology to enhance the learning process, also known as a structured approach (Gay, Stefanone, Grace-Martin, \& Hembrooke, 2001). Specific strategies have included short lectures followed by extensive practice on the laptop (Barak, Lipson, \& Lerman, 2006; Chompu-Inwai \& Doolen, 2006), small group exercises completing virtual experiments and real world projects (Kolar et al., 2002; Mackinnon \& Vibert, 2002), case studies (Mackinnon \& Vibert, 2002), and active use of course-related software (Barak et al., 2006; Kolar et al., 2002; Mackinnon \& Vibert, 2002). Research assessing the impact of a structured approach to using laptops in higher education has reported positive student attitudes about the impact of laptops on learning (Barak et al., 2006; Kolar et al., 2002; Mackinnon \& Vibert, 2002; Weaver \& Nilson, 2005), successful academic-based behaviours that support learning (Barak et al., 2006; Kolar et al., 2002; Mackinnon \& Vibert, 
2002; Nicol \& MacLeod, 2005; Weaver \& Nilson, 2005), and increased participation (Kolar et al., 2002).

\section{Benefits and Challenges of Using Laptops}

A review of the literature on laptop use inside higher education classrooms revealed two main benefits and two main challenges. Benefits, also referred to as on-task behaviours, included notetaking behaviour (Arend, 2005; Lindorth \& Bergquist, 2010; Skolnik \& Puzo, 2008) and specific academic laptop-based activities like searching for supplemental resources (Lindorth \& Bergquist, 2010) and working with specific software programs (Barak et al., 2006; Skolnik \& Puzo, 2008). Challenges, also know as off-task behaviours, typically included communication-based distractions such as instant messaging among peers for non-academic reasons (Fried, 2008; Hembrooke \& Gay, 2003; Mackinnon \& Vibert, 2002), sending personal emails (Barak et al., 2006; Fried, 2008; Hembrooke \& Gay, 2003; Skolnik \& Puzo, 2008), as well as entertainment-related challenges likes playing games (Barak et al., 2006; Fried, 2008; Hembrooke \& Gay, 2003; Skolnik \& Puzo, 2008) or watching movies (Barak et al., 2006).

\section{Purpose}

To date, no research has been conducted comparing unstructured and structured use of laptops. This kind of research could help determine whether teaching strategies influence in-class laptop behaviours. The purpose of the following study was to examine the impact of unstructured and structured use of laptops in higher education classrooms.

\section{Method}

\section{Sample}

The sample consisted of 177 higher education students ( 89 males, 88 females) enrolled in a small university (6000 students) within a large metropolitan area (3 million people). These students were in their first $(n=74)$, second $(n=59)$, third $(n=30)$, or fourth year $(n=13)$ of university. Their programs of study included social science $(n=108)$, business $(n=43)$, engineering $(n=11)$, science $(n=12)$, or health science $(n=3)$. Eighty-six percent $(n=153)$ of students reported that English was their first language. The average grade of first year students before they entered UOIT was 78.9 percent $(S . D .=6.3$, range 65 to 90 ). The average grade for second to fourth students was 74.6 percent $(S . D .=7.8$, range 59 to 90$)$. Almost $85 \%(\mathrm{n}=149)$ of the sample claimed that they were either proficient $(n=94)$ or very proficient $(n=55)$ at using computers. All students leased an IBM laptop imaged specifically to their selected programme and had ubiquitous wireless access to the Internet inside and outside their classrooms.

\section{Procedure}

Students were enrolled in one of two university courses (Philosophy or Issues in the Family). In both of these courses a series of laptop-based activities were implemented throughout the term (structured use of laptop condition). At the conclusion of a 13 week term, students from two higher education classes were invited to participate in an anonymous, online survey. Participation was voluntary and anonymous. It took approximately 5-10 minutes for students to complete the survey. Each student was asked to rate off-task and on-task behaviours for the course where structured use of laptops occurred. In addition, they were also asked to rate off-task and on-task behaviours for "another class" they participated in at the university. In this "other" class, the predominate mode of teaching was a traditional lecture using a PowerPoint presentation (unstructured use of laptops condition). 


\section{Data Sources}

\section{Independent variable}

Course format (structured and unstructured) was the main independent variable examined in this study. In a structured course format, a series of laptop-based activities was integrated with a traditional lecture and PowerPoint presentation. Examples of specific laptop-based tasks might include online surveys (e.g., assess gender roles, outlook on family issues), web-based research on assigned topics (e.g., social factors in historical perspective), interactive case studies to improve communication skills, creation of family genograms using online charting software, viewing online videos, reviewing published articles, consultation and discussion of websites (e.g., hate speech), and online philosophy games (e.g., philosophersnet.com). In an unstructured course format, the main method of content delivery was a traditional lecture using a PowerPoint presentation. Students were permitted to use their laptops in an unstructured and self-determined manner throughout the course.

\section{Dependent variables}

Based on previous research, six dependent variables were used in the current study to compare the impact of unstructured vs. structured use of laptops: note taking (on-task) and academic activities (on-task), personal email (off-task), instant messaging for personal reasons (off-task), games (off-task), and movies (off-task). Each student was asked to rate how much time they spent on each specific on- or off-task behaviour while participating in a course that followed either a structured or unstructured format for using laptops. Students selected five possible responses for each behaviour: $0=0 \%$ of the time, $1=1-25 \%$ of the time; $2=26-50 \%$ of the time, $3=$ $51-75 \%$ of the time; and $4=76-100 \%$ of the time. Specific wording of items is presented in Appendix A.

\section{Data Analysis}

Since subjects acted as their own controls, a MANOVA could not be used to analyze the multiple dependent variables in this study (Field, 2005). Therefore, eight paired t-tests were performed to assess differences between unstructured and structured use of laptops in the classroom for on-task (three tests) and off-task (five tests) behaviours.

\section{Results}

\section{On Task vs. Off Task Behaviours}

Before comparing unstructured to structured approaches to using laptops, it is worth examining the relative prevalence of on- and off-task behaviours. Mean ratings for both unstructured and structured on- task behaviour (note taking and academic activities) ranged from 2.77 to 3.01. Recall (from Appendix A) that a score of 3 indicated that a student spent 51 to $75 \%$ on class time on a specific task. Mean ratings for off-task behaviours ranged from 0.12 to 0.55 (less than $25 \%$ of class time) for entertainment-based activities (watching movies and playing games) and from 1.34 to 1.99 (between 25 and 50\% of class time) for communication activities (personal emails and instant messaging).

\section{On-Task Behaviours - Unstructured vs. Structured Use of Laptops}

Students who participated in courses with a structured format used laptops significantly more for note taking $(t(165)=3.42, p<.005)$ and engaging academic activities $(t(172)=2.91, p<.005)$ 
than in courses where an unstructured format was used. Total on task behaviour (a combination of note taking and academic activities) also favoured a structured approach $(t(164)=3.48, p<$ $.005)$. The effect sizes for these differences based on Cohen's d are considered small (Cohen, 1988, 1992). See Table 1 for the complete results.

\section{Table 1: On-Task Behaviours in Unstructured vs. Structured Use of Laptops}

\begin{tabular}{lllcccc}
\hline Behaviour & \multicolumn{2}{c}{ Unstructured } & \multicolumn{2}{c}{ Structured } & & \\
& Mean & S.D. & Mean & S.D. & t & Effect Size \\
\hline Taking Notes & 2.77 & $(1.10)$ & 3.01 & $(1.16)$ & $3.42 *$ & 0.21 \\
Academic Activities & 2.65 & $(1.15)$ & 2.88 & $(1.17)$ & $2.76 *$ & 0.20 \\
Total On-Task Behaviour & 5.46 & $(2.10)$ & 5.92 & $(2.09)$ & $3.48 *$ & 0.22 \\
\hline
\end{tabular}

* $\quad p<.005$

Note: Scores range from 0 to 4 and reflect how much time is spent on a task. $0=0 \%, 1=1-25 \% ; 2=26-50 \%, 3=51-75 \%$; and $4=76-100 \%$

\section{Off-Task Behaviours - Unstructured vs. Structured Use of Laptops}

A series of t-tests comparing unstructured to structured use of laptops with respect to off-task behaviours revealed significantly more time spent in an unstructured setting on non-academic emails $(t(165)=2.63, p<.01)$, non-academic instant messaging $(t(167)=2.19, p<.05)$, and game playing $(t(151)=3.59, p<.001)$. No significant difference between unstructured and structured formats was observed with respect to watching movies during class, although the frequency of this activity was quite low, so a meaningful comparison may not be possible. Time spent on total off-task behaviours (combination of all four off-task behaviours) was significantly higher for an unstructured approach $(t(140)=4.12, p<.001)$. The effect sizes for these differences based on Cohen's d are considered small (Cohen, 1988, 1992). See Table 2 for the complete results.

Table 2: Off-Task Behaviours in Unstructured vs. Structured Use of Laptops

\begin{tabular}{lcccccc}
\hline Behaviour & \multicolumn{2}{c}{ Unstructured } & \multicolumn{2}{c}{ Structured } \\
& Mean & S.D. & Mean & S.D. & t & $\begin{array}{r}\text { Effect } \\
\text { Size }\end{array}$ \\
& & & & & & 0.16 \\
Non-Academic Email & 1.51 & $(1.04)$ & 1.34 & $(1.02)$ & $2.63 * *$ & 0.12 \\
Non-Academic IM & 1.99 & $(1.31)$ & 1.83 & $(1.30)$ & $2.19 * * *$ & 0.12 \\
Playing Games & 0.55 & $(0.91)$ & 0.33 & $(0.63)$ & $3.59 *$ & 0.28 \\
Watching Movies & 0.18 & $(0.60)$ & 0.12 & $(0.49)$ & 1.98 & - \\
Total Off-Task Behaviour & 4.04 & $(2.65)$ & 3.49 & $(2.39)$ & $4.12 *$ & 0.16 \\
\hline$* \quad p<.001 ; * *$ & $p<.01 ; * * *$ & $p<.05$ & & & &
\end{tabular}

Note: Score range from 0 to 4 and reflect how much time is spent on a task. $0=0 \%, 1=1-25 \% ; 2=26-50 \%, 3=51-75 \%$; and $4=76-100 \%$ 


\section{Discussion}

The purpose of this study was to compare unstructured vs. structured use of laptops in higher education classrooms. The results indicate that students participated in significantly more ontasks behaviours in the form of note-taking and academic related tasks when a structured approach to using laptops was employed. Furthermore, time spent on off-task laptop behaviours, such as sending personal emails and instant messages, as well as playing games, was significantly less with structured approach. These findings are consistent with previous research indicating that structured use of laptops results in more positive behaviours than unstructured use (Barak et al., 2006; Baron et al., 2008; Hall \& Elliot, 2003; Kolar et al., 2002; Mackinnon \& Vibert, 2002; McVay et al., 2005; Nicol \& MacLeod, 2005; Weaver \& Nilson, 2005). However, this study provides more compelling evidence because unstructured and structured uses of laptops were directly compared using a common metric.

A second key finding is that on-task laptop behaviours appear more prevalent than off-task behaviours, regardless of whether a structured or non-structured format of teaching was used. Notetaking and academic activities were reported, on average, to take up 80-90\% of class time. Communication and entertainment-based activities were far less prevalent. It is possible that some professors may be making incorrect assumptions about student laptop behaviour when they ban laptops or turn off wireless access (Kladko, 2005; McWilliams, 2005; Schwartz, 2003; Szaniszlo, 2006; Young, 2006). While it is clear that students participate in non-academic activities, the main use for laptops appears to be to support academics.

A third noteworthy result is that note-taking was the number one activity in both structured and unstructured lesson formats. If students are taking notes 75 to $100 \%$ of the time in class, it is reasonable to assume that they are listening to a lecture, rather than participating in active knowledge building. Even though a concerted effort was made to use laptops in an active and meaningful way during structured lessons, the main delivery method used was a lecture with a supporting PowerPoint presentation. Considerable evidence suggests that lectures are less effective than classes where self-directed learning, constructive, problem-based activities are pursued (Bransford, Brown, \& Cocking, 2000; Hughes \& Mighty, 2010, Medina, 2008; Willingham, 2009). More research is needed focussing on the challenges professors experience when trying to shift from a didactic to an active mode of teaching. Professors clearly have the content knowledge of their subjects' areas but may need to acquire the pedagogical and technology-based knowledge to successfully integrate laptops into higher education (American Association of Colleges for Teacher Education, 2008).

\section{Caveats and Future Research}

The purpose of this study was to explore the role that a structured approach (active use of laptops) might play in helping to make laptops a more productive tool in higher education classrooms. The preliminary evidence suggests that even a relatively modest attempt to integrate meaningful laptop activities into a class results in more time being spent on activities that support learning. However, there are still a number of unanswered questions that need to be addressed.

First, the precise impact of specific teaching strategies that lead to positive or negative laptop behaviour and ultimately improved learning needs to be examined. In other words, simply increasing the frequency of laptop use may not result in more productive use. Evaluating the impact of explicit techniques of using laptops would particularly helpful to instructors and researchers.

Second, the impact of subject area and potential teaching approaches with laptops needs to be explored. Preliminary evidence indicates that effective use of laptops is generally associated with courses that are traditionally associated with technology including business (Mackinnon \& Vibert, 2002) programming (Barak et al., 2006) and engineering (Chompu-inwai \& Doolen, 
2006; Kolar et al., 2002; Nicol \& MacLeod, 2005). One the other hand, social science courses in psychology (Fried, 2008) and communications (Grace-Martin \& Gay, 2001) have shown limited success or negative results. It is possible that it is more challenging to effectively integrate laptops into courses where technology does not have an obvious application.

Finally, as stated earlier, more research is needed on the potential challenges an instructor faces when attempting to integrate laptops into a course including personal teaching philosophy, time required to develop and learn new technologies, the possibility that not all students will have laptops, the size of class, technological limitations, software availability, pressure to cover excessive content in a short time period, and motivation to change.

\section{Summary}

This study compared unstructured (PowerPoint lecture) to structured (active use of laptops integrated into a PowerPoint lecture). The data suggested that a structured approach leads to more productive use of laptops inside higher education classrooms. The simple conclusion from this paper is that if you don't intentionally and meaningfully use laptops in the classroom, students will engage in a wide range of non-productive laptop behaviours.

\section{References}

American Association of Colleges for Teacher Education (AACTE). (2008). Handbook of technological pedagogical content knowledge (TPCK). New York: Routledge.

Arend, B. D. (2004). New patterns of student engagement. About Campus, 9(3), 30-32.

Barak, M., Lipson, A., \& Lerman, S. (2006). Wireless laptops as means for promoting active learning in large lecture halls. Journal of Research on Technology in Education, 38(3), 245-263.

Baron, A. E., Feyten, C. M., Venable, M., Hilbelink, A., Hogarty, K. Y., Kromrey, J. D., \& Lang, T. R. (2008). Laptop computers in teacher preparation: Lesson learned from the university of South Florida implementation. Journal of Computing in Higher Education, 20(1), 95-117. doi: 10.1007/BF03033433

Bransford, J. D., Brown, A. L., \& Cocking, R. R. (Eds.). (2000). How people learn. Washington, DC: National Academy Press.

Chompu-inwai, R., \& Doolen, T. L. (2006). A methodology for studying the impact of laptops in engineering. 36th ASEE/IEEE Frontiers in Education Conference, San Diego, CA. doi: 10.1109/FIE.2006.322680

Cohen, J. (1988). Statistical power analysis for the behavioural sciences (2nd ed.). New York: Academic Press.

Cohen, J. (1992). A power primer. Psychological Bulletin, 112(1), 155-159. doi: 10.1037/00332909.112.1.155

Fang, B. (2009). From distraction to engagement: Wireless devices in the classroom. Educause Quarterly, 32(4). Retrieved from

http://www.educause.edu/EDUCAUSE+Quarterly/EDUCAUSEQuarterlyMagazineVolum/FromDistra ctiontoEngagementWir/192959

Field, A. (2005). Discovering statistics using SPSS. Thousand Oaks, CA: Sage Publications.

Fried, C. B. (2008). In-class laptop use and its effects on student learning. Computers \& Education, 50(3), 906-914. doi: 10.1016/j.compedu.2006.09.00

Furedy, J. J. (2000). Seven principles of higher education: A primer. Academic Questions, 13(4), 44-51.

Gay, G., Stefanone, M., Grace-Martin, M., \& Hembrooke, H. (2001). The effects of wireless computing in collaborative learning environments. International Journal of Human-Computer Interaction, 13(2), 257-276. doi: 10.1207/S15327590IJHC1302_10

Goffman, E. (1963). Behavior in public places. New York: Free Press. 
Grace-Martin, M., \& Gay, G. (2001). Web browsing, mobile computing and academic performance. Educational Technology and Society, 4(3), 95-107. Retrieved from http://www.ifets.info/journals/4 3/grace martin.pdf

Hall, M., \& Elliot, K. M. (2003). Diffusion of technology into the teaching process: Strategies to encourage faculty members to embrace the laptop environment. Journal of Education for Business, 78(6), 301-307. doi: 10.1080/08832320309598617

Hembrooke, H., \& Gay, G. (2003). The laptop and the lecture: The effects of multitasking in learning environments. Journal of Computing in Higher Education, 15(1), 46-64. doi: 10.1007/BF02940852

Hughes, J. C., \& Mighty, J. (2008). Taking stock: Research on teaching and learning in higher education. Montreal, Quebec: McGill-Queen's University Press.

Kladko, B. (2005, April 16). Wireless classrooms: Tool or distraction? The Record, p. A1.

Kolar, R. L., Sabatini, D. A., \& Fink, L. D. (2002). Laptops in the classroom: Do they make a difference? Journal of Engineering Education, 91(4), 397-401. Retrieved from http://findarticles.com/p/articles/mi_qa3886/is_200210/ai_n9115111/?tag=content;col1

Lindroth, T., \& Bergquist, M. (2010). Laptopers in an educational practice: Promoting the personal learning situation. Computer \& Education, 54(2), 311-320. doi: 10.1016/j.compedu.2009.07.014

Mackinnon, G. R., \& Vibert, C. (2002). Judging the constructive impacts of communication technologies: A business education study. Education and Information Technologies, 7(2), 127-135.

McVay, G. J., Snyder, K. D., \& Graetz, K. A. (2005). Evolution of a laptop university: A case study. British Journal of Educational Technology, 36(3), 513-524. doi: 10.1111/j.1467-8535.2005.00487.x

Medina, J. (2008). Brain rules. Seattle, WA: Pear Press.

McWilliams, G. (2005, October 14). The laptop backlash. The Wallstreet Journal, p. B1.

Montgomery, K. C. (2009). Generation digital. MA: MIT Press.

Nicol, D. J., \& MacLeod, I. A. (2005). Using a shared workspace and wireless laptops to improve collaborative project learning in an engineering design class. Computers \& Education, 44(4), 459-475. doi: 10.1016/j.compedu.2004.04.008

Palfrey, J., \& Gasser, U. (2008). Born digital. New York: Basic Books.

Schwartz, J. (2003, January 2). Professors vie with Web for class's attention. New York Times, p. A1.

Skolnik, R., \& Puzo, M. (2008). Utilization of laptop computers in the school of business classroom. Academy of Educational Leadership Journal, 12(2), 1-10. Retrieved from http://findarticles.com/p/articles/mi_hb6044/is 200805/ai n32303961/?tag=content;col1

Smith, S. D., Salaway, G., \& Caruso, J. B. (2009). The ECAR study of undergraduate students and information technology, Educause Center for Applied Research, 6. Retrieved from http://net.educause.edu/ir/library/pdf/ers0906/rs/ers0906w.pdf

Szaniszlo, M. (2006, June 4). Harvard profs lay down law: No laptops in class. The Boston Herald, p. A6.

Tapscott, D. (2008). Grown up digital: How the net generation is changing your world. New York: McGraw-Hill.

Weaver, B. E., \& Nilson, L. B. (2005). Laptops in class: What are they good for? What can you do with them? New Directions in Teaching and Learning, 101, 3-13. doi: 10.1002/t1.181

Willingham, D. T. (2009). Why don't students like school? San Francisco: Jossey-Bass.

Wurst, C., Smarkola, C., \& Gaffney, M. A. (2008). Ubiquitous laptop usage in higher education: Effects on student achievement, student satisfaction, and constructivist measures in honors and traditional classrooms. Computers \& Education, 51(4), 1766-1783. doi: 10.1016/j.compedu.2008.05.006

Young, J. R. (2006, June 2). The fight for classroom attention: professor vs. laptop. Chronicle of Higher Education, p. A27-A29. 


\section{Appendix A - On- and Off Task Laptop Behaviours Survey}

\section{On-Task Behaviours}

1. How much of the lecture time in this course do you use the laptop to take notes or follow the lecture?

a. $76-100 \%$ of the lecture time (4)

b. $51-75 \%$ of the lecture time (3)

c. $26-50 \%$ of the lecture time (2)

d. $1-25 \%$ of the lecture time (1)

e. $0 \%$ of the lecture time $(0)$

2. How much of the lecture time in this course do you use the laptop for academic purposes relating to this class (i.e., following lecture, doing in-class assignments or activities, viewing course outline, etc.)?
a. $76-100 \%$ of the lecture time (4)
b. $51-75 \%$ of the lecture time (3)
c. $26-50 \%$ of the lecture time (2)
d. $1-25 \%$ of the lecture time (1)
e. $0 \%$ of the lecture time $(0)$

\section{Off-Task Behaviours}

3. How much of the lecture time in this course do you use the laptop for email of any kind (Hotmail, Yahoo, gmail, etc.) for purposes other than this course?
a. $76-100 \%$ of the lecture time (4)
b. $51-75 \%$ of the lecture time (3)
c. $26-50 \%$ of the lecture time (2)
d. $1-25 \%$ of the lecture time (1)
e. $0 \%$ of the lecture time $(0)$

4. How much of the lecture time in this course do you use the laptop for instant messaging (msn, etc.) for purposes other than the course?
a. $76-100 \%$ of the lecture time (4)
b. $51-75 \%$ of the lecture time (3)
c. $26-50 \%$ of the lecture time (2)
d. $1-25 \%$ of the lecture time (1)
e. $0 \%$ of the lecture time $(0)$

5. How much of the lecture time in this course do you use the laptop to play games?
a. $76-100 \%$ of the lecture time (4)
b. $51-75 \%$ of the lecture time (3)
c. $26-50 \%$ of the lecture time (2)
d. $1-25 \%$ of the lecture time (1)
e. $0 \%$ of the lecture time $(0)$

6. How much of the lecture time in this course do you use the laptop to watch movies?
a. $76-100 \%$ of the lecture time (4)
b. $51-75 \%$ of the lecture time (3)
c. $26-50 \%$ of the lecture time (2)
d. $1-25 \%$ of the lecture time (1)
e. $0 \%$ of the lecture time $(0)$ 


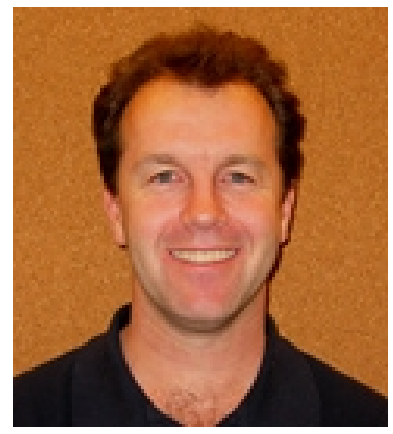

\section{Biographies}

Robin Kay, Ph.D. is an Associate Professor in the Faculty of Education at the University of Ontario Institute of Technology. He has published over 50 articles and chapters in the area of computers in education, presented numerous papers at 15 international conferences, refereed five prominent computer education journals, and taught computers, mathematics, and technology for over 20 years. Current projects include research on laptop use in teacher education, classroom response systems, web-based learning tools, and factors that influence how students learn with technology.

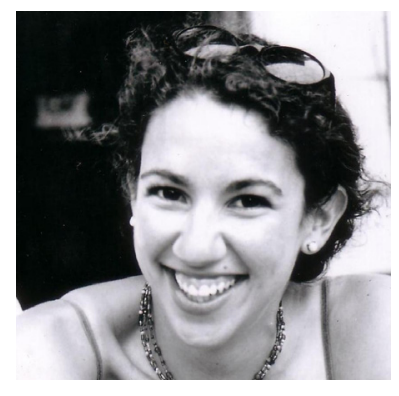

Sharon Lauricella, Ph.D. is an Assistant Professor in the Faculty of Social Science and Humanities at the University of Ontario Institute of Technology. She is an award-winning instructor, having received the UOIT Teaching Award and Social Science and Humanities Teaching Excellence Award. Her research interests are in the areas of communication in education, including use of technology, SMS, podcasting and online communication tools. Current projects include laptop use in undergraduate education, learning practices such as meditation via podcast, and use of SMS as an educational communication tool. 